\title{
Modeling and 3D Simulation of the Mould Compression and Resin Flow for Force-Controlled Compression Resin Transfer Moulding
}

\author{
Bo YANG *, Shilong WANG, Qian TANG
}

Chongqing University, State Key Laboratory of Mechanical Transmission, Chongqing 400044, Peoples R China

crossref http://dx.doi.org/10.5755/j01.ms.25.1.19134

Received 27 September 2017; accepted 18 February 2018

\begin{abstract}
Since the existence of the complicated coupling between mould compression and resin flow, the full 3D simulation of the filling process in force-controlled compression resin transfer moulding (CRTM) has not been realized, especially when the resin flow front is irregular on the thickness direction during thick part moulding. In this paper, the coupled resin flow and mould compression behaviors are investigated firstly, a equivalent spring method is proposed to describe the preform compaction. The lubrication effect is taken into account, so the mould compression speed can be determined when the resin flow front is irregular on the thickness direction. Then the Volume of Fluid (VOF) two-phase model is established to express the resin-air flow in narrow gap and preform simultaneously, in which the narrow gap is considered as 3D area without flow resistance. Finally, the 3D numerical method for solving the above mathematical models is developed. In this method, the changing of the mould cavity is simulated by moving mesh technology, and the master-slave element method is used to simulate the resin squeezing from the infiltrated preform. Comparisons with analysis results are provided to prove the correctness of the above method, and two 3D examples are given to demonstrate the simulating capability.

Keywords: force-controlled CRTM, preform compaction, mould filling, 3D simulation.
\end{abstract}

\section{INTRODUCTION}

Compression resin transfer moulding (CRTM) increasingly becomes an important processing technology to fabricate large-scale or high fiber content composite parts. In CRTM, a partially-open mould is used, the initial thickness of the cavity $h_{i n i}$ is larger than the thickness of final product $h_{\text {final }}$, sometimes a narrow gap between the mould platen and the preform is set to accelerate the resin flow. The filling process of CRTM exhibits three distinct stages as shown in Fig. 1: 1) resin injection into the cavity to fill the narrow gap or infiltrate partial preform; 2) closing the resin inlet and compressing the mould platen until all resin is squeezed into the preform; 3) continue compaction until the desired thickness is achieved.

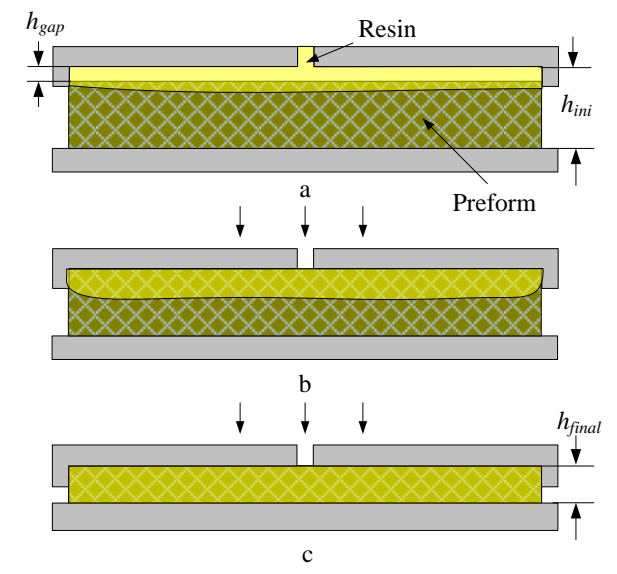

Fig. 1. Three filling stages of CRTM: $a-$ resin injection; $b-$ closing the gap; c-preform compaction

\footnotetext{
${ }^{*}$ Corresponding author. Tel.: +86-18223132847; fax: +86-02365106436. E-mail address: yangbo61@ cqu.edu.cn (B. Yang)
}

It should be noted that the mould compression can be controlled either by force or by speed, which are named as force-controlled and speed-controlled CRTM, respectively. Analysis of the preform compaction and resin flow during the mould-filling process of CRTM is a key step of the mould design and process parameter selection.

Many papers dealt with the numerical simulation of the filling processes of the conventional resin transfer moulding (RTM) [1-7] and speed-controlled CRTM [8-15]. In the speed-controlled CRTM, the mould compression speed is explicitly known, which brings much convenience to estimate the preform deformation and simulate the mould-filling process. Force-controlled CRTM is the opposite, the compression speed needs to be determined from the coupled resin flow and mould compression behaviors [16], while the complexity of the preform compaction characteristics makes the above coupled equations difficult or even impossible to be solved directly. Merotte et al. $[17,18]$ modeled the resin flow in the last two phases of force-controlled CRTM as a 1D flow to estimate the compression time, they developed a numerical solution to predict the flow front progression and the preform deformation. Verleye and Walbran et al. $[19,20]$ developed an iterative procedure for the simulation of force controlled RTM and CRTM processes, which includes the possibility of ramped increase in force applied to the mould, but their algorithm can only be used for the moulding simulation of thin parts. Mamoune et al. [21] developed a new numerical modeling of CRTM process with mould compression under a force, and it was applied to a series of parametric studies, considering the effects of part size and fiber volume fraction on the mouldfilling time. Yang et al. [22] introduced an alternative approach to simulate the resin flow and stress distributions during mould-filling process, which can be used in force- 
controlled CRTM, while it is also only effective in thin part moulding simulation. From the above analyses, we can find that the previously proposed methods for the mould-filling simulation of force-controlled CRTM are just valid for $1 \mathrm{D} / 2 \mathrm{D}$ resin flow or thin part moulding, when the resin flow front is irregular on the thickness direction during thick part moulding, none of them can be adopted.

Therefore, a full 3D filling simulation tool for forcecontrolled CRTM is urgently needed; this paper intends to develop an effective and convenient numerical method to meet this need. The coupled resin flow and mould compression behaviors are investigated firstly, an equivalent spring method is proposed to describe the preform compaction characteristics in which the lubrication effect is taken into account, so the mould compression speed under an applied clamping force can be determined when the resin flow front is irregular on the thickness direction. Then a unified mathematical model is established to express the resin-air flow in narrow gap and preform simultaneously, in which the narrow gap is considered as 3D area without flow resistance. Finally, the 3D numerical solving method of the above mathematical models is developed, in this method, the changing of the mould cavity is implemented by the moving mesh technology, and the master-slave element method is used to simulate the resin squeezing from the infiltrated preform.

\section{MODELING OF THE MOULD COMPRESSION AND RESIN FLOW}

\subsection{Mould compression}

In force-controlled CRTM, mould compression speed under the applied clamping force during the last two stages of mould-filling is unknown, it needs to be calculated from the force bearing analysis on the mould platen. Suppose the compression speed is constant, the total applied clamping force is equal to the sum of resin reaction force and preform reaction force (i.e. perform compaction force), which can be written as

$$
F_{\text {total }}=F_{r}+F_{f}, F_{r}=\int_{A} p \mathrm{~d} A, F_{f}=\int_{A} \sigma_{f} \mathrm{~d} A,
$$

where $F_{\text {total }}$ is the total applied clamping force, $F_{r}$ is the resin reaction force, $F_{f}$ is the preform reaction force, $p$ is the resin pressure, $A$ is the mould platen surface area, $\sigma_{f}$ is the stress exert on the preform.

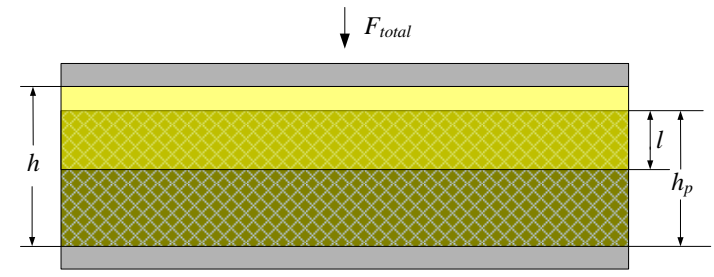

Fig. 2. Calculation of the mould compression speed for gap closure stage

Suppose the narrow gap above the preform is filled by the injected resin before compression, and the through thickness permeability value of the preform $K_{z z}$ is much smaller than the permeability in the gap, we can assume that there is only resin flow on the thickness direction as shown in Fig. 2 during the gap closure stage [18]. Since the preform deformation during this stage is negligible [13-16], the mould compression speed $r_{c}$ can be computed according to Darcy's law:

$$
r_{c}=\frac{K_{z z}}{\mu} \cdot \nabla p=\frac{K_{z z}}{\mu} \cdot \frac{F_{\text {total }}}{A l},
$$

where $\mu$ indicates the viscosity, $l$ indicates the thickness of the saturated preform, $v f$ indicates the fiber content of preform.

During the preform compaction, the mould compression speed should be calculated from the preform compaction velocity. Since the lubrication effect of resin on preform, the saturated and dry preforms have different compaction behaviours, therefore, computation of the preform compaction velocity is much more complicated. From Eq. 1, we can obtain the preform compaction force $F_{f}$ :

$F_{f}=F_{\text {total }}-F_{r}=F_{\text {total }}-\int_{A} p \mathrm{~d} A$.

The preform in mould cavity during the third stage as shown in Fig. 3 a can be divided into $m$ subparts ( $m=10$ in the figure), we can suppose that the relationship between the compaction force and velocity of each subpart at current time can be expressed by

$F_{f, i}=r_{p, c} \cdot E_{i}\left(s_{w e t}, v_{f}\right), i=0,1, \ldots, m-1$,

where $F_{f, i}$ indicates the compaction force exerted on the $i$ th subpart of the preform, $r_{p, c}$ indicates the compaction velocity, $E_{i}$ is the stiffness coefficient of the $i$-th subpart.

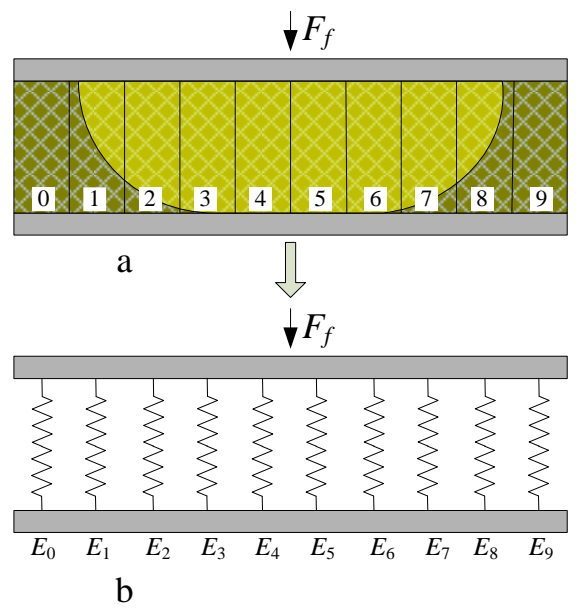

Fig. 3. Equivalent model of the preform compression

It should be noted that the compaction behaviour of preform is viscoelastic, so $E_{i}$ is not only related to the infiltration state $s_{w e t}$, but also has close relations with fiber volume fraction of the subpart. As a result, the whole preform can be equivalent to a parallel system of spring units as shown in Fig. 3 b, which has the following deduction:

$F_{f}=\sum_{i=0}^{m-1} F_{f, i}=r_{p, c} \cdot \sum_{i=0}^{m-1} E_{i}\left(s_{w e t}, v_{f}\right) \cdot$

Since the mould compression speed can be calculated from the preform compaction velocity, the following equation can be used to compute $r_{c}$ : 


$$
r_{c}=r_{p, c}=\frac{F_{f}}{\sum_{i=0}^{m-1} E_{i}\left(s_{w e t}, v_{f}\right)} .
$$

The equivalent spring stiffness values $\left(E_{0}, E_{1}, \ldots, E_{i}\right)$ of the preform subparts need to be determined from the preform compaction characteristics which will be discussed in the next section.

\subsection{Compaction and permeability models of preform}

The viscoelastic compaction model is adopted to fully express the dynamic compaction characteristics of preform, details of this model can be found [23, 24]. According to the viscoelastic compaction model, the compaction stress of preform can be described as

$$
\begin{aligned}
& \sigma_{f}\left(v_{f}, r_{p, c}\right)=\left[\sigma_{\alpha}\left(r_{p, c}\right) \sigma_{\beta}\left(v_{f}\right)\right] / \lambda= \\
& \left\{\sigma_{\alpha}(\infty)-\left[\sigma_{\alpha}(\infty)-\sigma_{\alpha}(0)\right] \frac{1}{N_{\alpha}} \sum_{i=1}^{N_{\alpha}} e^{-\alpha_{i}\left(r_{p, c} / r_{p, c}^{r f}\right)}\right\}\left\{\left\{\sum_{i=0}^{N_{\beta}} \beta_{i}\left(v_{f}-v_{f}^{d a t}\right)^{i}\right\} / \lambda\right.
\end{aligned}
$$

where $\sigma_{\alpha}\left(r_{p, \mathrm{c}}\right)$ is the stress as a function of compaction speed at a reference fiber content $v_{f}^{r e f}, \sigma_{\beta}\left(v_{f}\right)$ is the stress response as a function of fiber content at a reference compaction speed $r_{p, c}{ }^{r e f}$, the constant $\lambda=\sigma_{\alpha}\left(r_{p, c}{ }^{r e f}\right)=\sigma_{\beta}\left(v_{f}^{r e f}\right)$. $\sigma_{\alpha}(0)$ and $\sigma_{\alpha}(\infty)$ are respectively the stresses at the "very slow" and "very fast" speeds at the reference fiber content, $N_{\alpha}$ and $N_{\beta}$ are the numbers of exponential terms, $v_{f}^{d a t}$ is some datum volume fraction. Different model parameter sets $\left(\beta_{i}, \alpha_{i}, N_{\beta}, N_{\alpha}\right)$ are used to reflect the compaction behaviours of different infiltration states in the viscoelastic compaction model.

During the preform compaction, the following relation between fiber volume fraction and preform thickness can be established:

$v_{f}=h_{p, i n i} \cdot v_{f, i n i} / h_{p}$,

where $h_{\mathrm{p}}$ is the preform thickness, $h_{p, i n i}$ indicates the initial preform thickness, $v_{\mathrm{f} \text {,ini }}$ is the initial fiber volume fraction of the preform. Preform permeability $K$ is a key parameter of the flow simulation, with the increase of the fiber content, it decreases rapidly. The Kozeny-Carman equation is one of the most popular permeability models $[25,26]$ :

$K\left(v_{f}\right)=k \frac{\left(1-v_{f}\right)^{3}}{v_{f}^{2}}$,

where $k$ is parameter determined from experiment.

\subsection{Modeling of flow}

During the mould-filling of CRTM, resin infiltrates the preform and expels air from the cavity, this is a two-phase flow process. The Volume of Fluid (VOF) method is a relatively mature interface tracking technique in Eulerian grids for two-phase flow, and it has been widely used in the simulation of RTM processes, so the VOF two-phase model is used to describe the resin flow during the mouldfilling process of CRTM in this paper [9, 27]:

$$
\rho_{\text {fluid }} \frac{\partial \bar{u}}{\partial t}+\rho_{\text {fluid }} \bar{u} \cdot \nabla \bar{u}=-\nabla p+\mu_{\text {fluid }} \Delta \bar{u}-\frac{\mu_{\text {fluid }} \bar{u}}{K}
$$

where $\rho$ indicates the density, the subscript fluid denotes the fluid type, $u$ indicates the velocity, $\bar{u}$ indicates the Darcy velocity:

$\bar{u}=u \cdot\left(1-v_{f}\right) \cdot$

The fluid physical properties $\Phi$ (indicates $\rho$ or $\mu$ ) can be obtained by

$\Phi(x, t)=C(x, t) \Phi_{r}+[1-C(x, t)] \Phi_{a}$,

where $\boldsymbol{x}$ is the location of fluid, $\mathrm{C}$ is the resin volume fraction in a computational cell.

The following equation is used to track the fluid interfaces in VOF:

$\partial C / \partial t+\nabla \cdot(\bar{u} C)=0$.

Assuming the fluid is incompressible, the mass conservation for flow in cavity can be expressed by $[9,13,14]$

$\nabla \cdot \bar{u}=-\frac{1}{h} \cdot \frac{\mathrm{d} h}{\mathrm{~d} t}=-\frac{1}{h} \cdot r_{c}$

where $h$ indicates the thickness of the mould cavity.

Eq. 10, Eq. 13 and Eq. 14 describe the resin-air twophase flow during the mould-filling process of forcecontrolled CRTM.

\section{NUMERICAL APPROACH AND IMPLEMENTATION}

During the simulation of the preform compaction stage, the equivalent spring stiffness values $E_{i}$ of the preform subparts need to be determined before computing the mould compression speed by Eq. 6. Since the preform compaction model (Eq. 7) is too complex to obtain the mathematical expressions of the stiffness values, we estimate them by data interpolation. The speed-stress curve of preform compaction as shown in Fig. 4 can be drawn from the compaction model (Eq.7), then the stiffness values can be calculated by

$E_{i}^{n}=\frac{F_{i}^{n-1}}{r_{p, c}^{n-1}}=\frac{\sigma_{f, i}^{n-1} \cdot A_{i}}{r_{p, c}^{n-1}}$,

where $A_{i}$ is the area of the $i$-th preform subpart contacted with the moving platen of the mould, $\sigma_{f, i}{ }^{n-1}$ is the compaction stress on the $i$-th subpart of the preform which is obtained from the compaction speed-stress curve as shown in Fig. 4. Since the stiffness values vary with the infiltration state and fiber volume fraction, we have to recalculate them for every subpart at each time step, simulation results of the last time step $\left(\sigma_{f, i}{ }^{n-1}\right.$ and $\left.r_{p, c}{ }^{n-1}\right)$ are used to estimate the stiffness values at the current time step $E_{i}{ }^{n}$.

The implementation of the above simulation method is accomplished in the Fluent environment by UDF (UserDefined Function), a self-defined momentum source is programmed and exerted into the Fluent solver to carry out the changing flow resistance at each node. In order to simulate the 3D flow, the dynamic changing of the mould cavity is implemented by the moving mesh technology as 
shown in Fig. 5, the moving velocity and orientation are both adjustable.

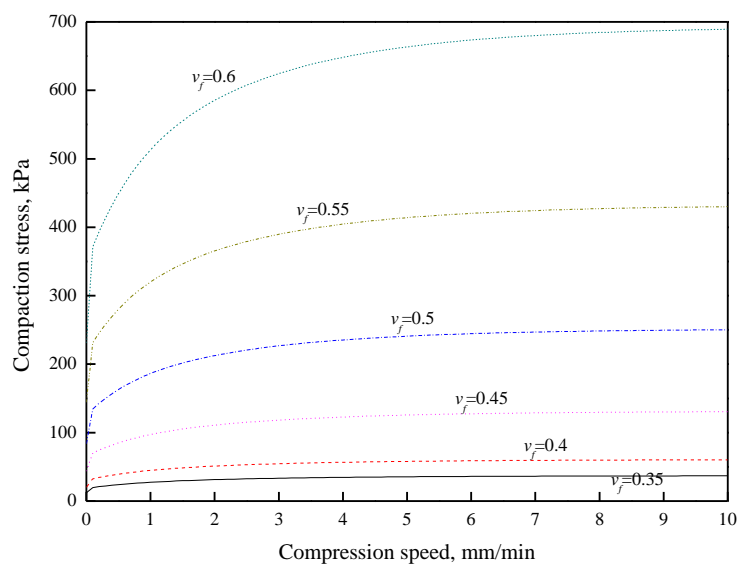

Fig.4. An example of preform compaction speed-stress curve

Since the variation in cavity thickness is directly achieved by the moving mesh, the mass conservation equation (16) needs to be replaced by

$\nabla \cdot \overline{\boldsymbol{u}}=0$

To ensure mass conservation, the master-slave element method is employed to calculate the resin squeezing from the infiltrated preform. The detailed information on implementation method and parameters calculation can be found [27].

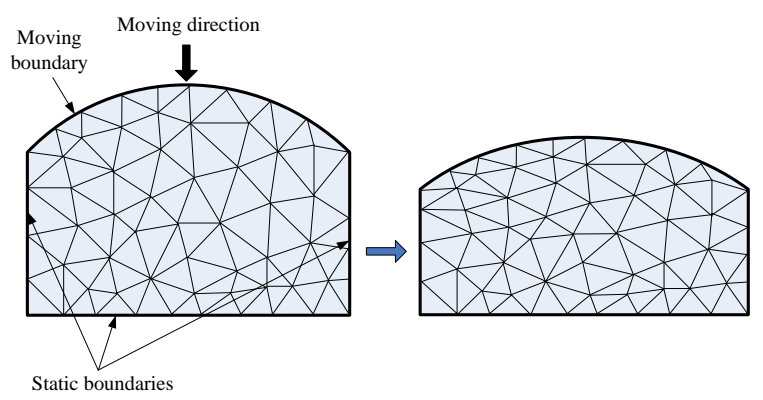

Fig. 5. Demonstration of moving mesh

\section{VALIDATION OF NUMERICAL SIMULATION}

The validity of the numerical approach presented in this study is checked with analytical solution of onedimensional flow in a rectangular mould cavity. The preform is the $650 \mathrm{~g} / \mathrm{m}^{2}$ woven glass whose compaction model parameters can be found [23]. Dimensions of the rectangular cavity are 220,50 and $10 \mathrm{~mm}$. The mould cavity and preform have the same initial thickness, the initial porosity of the preform is 0.6 and the permeability model parameter $k$ on the flow direction is $4 \times 10^{-10}$. Since there is no open gap in the mould cavity, the total filling process only involves two stages: resin injectin and preform compaction. Resin is injected at a fixed inlet pressure of $200 \mathrm{kPa}$ during resin injection stage and the total clamping force is $1 \mathrm{kN}$ during the preform compaction stage. The final thickness of the preform is $8 \mathrm{~mm}$ and the resin viscosity is $0.4 \mathrm{~Pa}$. The threedimensional simulation model and the boundary conditions are shown in Fig. 6.

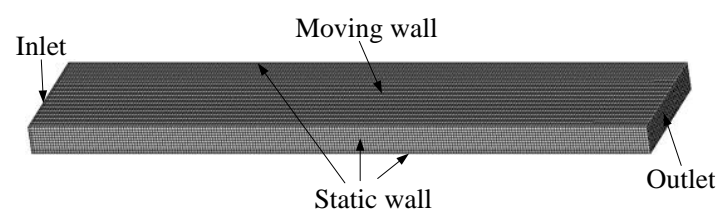

Fig. 6. Simulation model of one-dimensional flow

The comparison of the progression of the flow front is shown in Fig. 7 a. The analytical result of the resin injection stage is obtained by integrating Darcy's law:

$t_{\text {inj }, \text { ana }}=\frac{\left(1-v_{f}\right) \mu}{2 K} \cdot \frac{l^{2}}{\left(p_{\text {in }}-p_{\text {out }}\right)}$,

where $p_{\text {in }}$ and $p_{\text {out }}$ are the injection pressure and outlet pressure, $l$ indicates the length of the saturated preform. The analytical result of the preform compaction stage is computed by the equation given in [17], which is only effective for 1D flow. At $t=23.9 \mathrm{~s}$, the desired amount of resin is completely injected and then the mould is compressed under the constant force $(1 \mathrm{kN})$ until the final thickness is obtained and all the preform is infiltrated (at $t=40 \mathrm{~s}$ ). As can be seen in the figure, the simulation result of the resin injection stage is consistent with the analytical values, while the simulated flow front velocity is a little smaller than the analytical values during preform compression stage, which may be caused by the following reasons: (1) The dynamic characteristics of the preform compaction and the inconsistent flow front as shown in Fig. $7 \mathrm{~b}$ are not considered in the analytical values; (2) The effect of boundary layer thickness during injection; (3) Coefficient of thermal expansion (CTE) mismatch between the resin and preform.

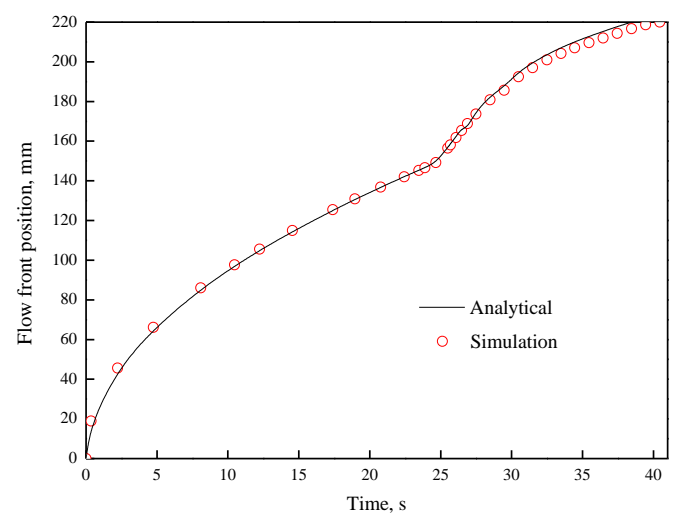

a

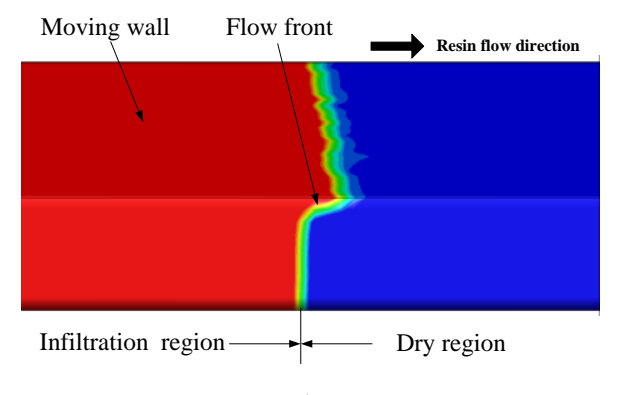

$\mathrm{b}$

Fig. 7. Comparison of the progression of the flow front: $a$-comparison of the progression; $b$-flow front during preform compaction stage 
Fig. 8 presents the mould compression speed and thickness evolutions during the preform compaction stage. Since the total clamping force is constant, the compression speed reduces gradually as the decrease of the preform thickness, at the end of the filling process, the compression is only about $2 \mathrm{~mm} / \mathrm{min}$. A good agreement can be seen from the comparison between the simulated and analytical thicknesses, the causes of errors have been discussed in the previous paragraph.

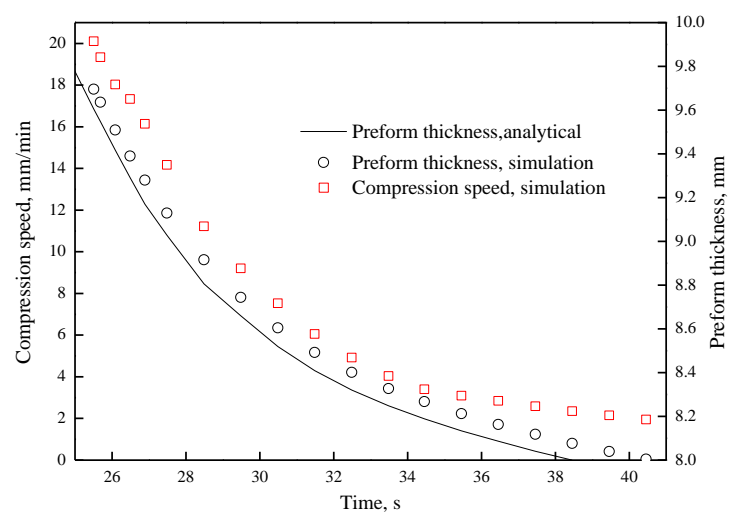

Fig. 8. Mould compression speed and preform thickness traces during preform compaction stage of one-dimensional flow

\section{THREE-DIMENSIONAL FLOW EXAMPLES}

Two 3D numerical simulations are given to demonstrate the application of 3D flow simulation and analysis of mould-filling process in force-controlled CRTM on different filling parameters. Fig. 9 shows the simulation mesh of the two examples, the preform used in simulations is CSM (Chopped Strand Mat) and its compaction properties are listed in Table 1.

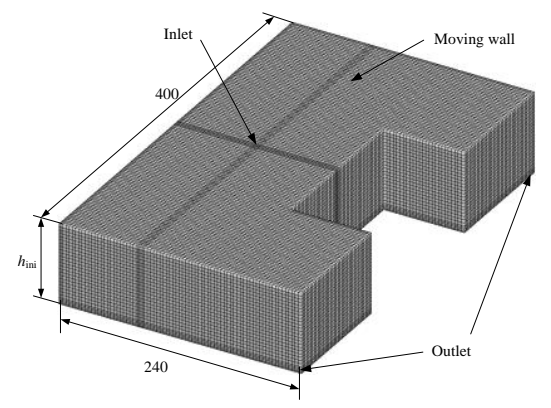

Fig. 9. Simulation model for both examples

Table 1. Viscoelastic compaction model parameters for CSM preform

\begin{tabular}{|c|c|c|c|c|c|}
\hline \multicolumn{6}{|c|}{$u_{\text {cref }}=2 \mathrm{~mm} / \mathrm{min}, v_{\text {fref }}=0.425, N_{\alpha}=4, N_{\beta}=4, N A=2, v_{f d a t}=0.425$} \\
\hline \multicolumn{6}{|l|}{ Dry } \\
\hline$\alpha_{1}$ & 8000 & $\sigma_{\alpha}(\infty)$ & 90000 & $\beta_{2}$ & 7890000 \\
\hline$\alpha_{2}$ & 2.9 & $\sigma_{\alpha}(0)$ & 30000 & $\beta_{3}$ & 2825300 \\
\hline$\alpha_{3}$ & 0.8 & $\beta_{0}$ & 76129 & $\beta_{4}$ & 47027000 \\
\hline$\alpha_{4}$ & 0.85 & $\beta_{1}$ & 1193200 & & \\
\hline \multicolumn{6}{|l|}{ Wet } \\
\hline$\alpha_{1}$ & 80 & $\sigma_{\alpha}(\infty)$ & 94000 & $\beta_{2}$ & 7786100 \\
\hline$\alpha_{2}$ & 1.5 & $\sigma_{\alpha}(0)$ & 30000 & $\beta_{3}$ & 2395900 \\
\hline$\alpha_{3}$ & 1.23 & $\beta_{0}$ & 79721 & $\beta_{4}$ & 30040000 \\
\hline$\alpha_{4}$ & 1.25 & $\beta_{1}$ & 1249100 & & \\
\hline
\end{tabular}

The mould filling conditions for each example are given in Table 2. The initial cavity thickness is larger than the initial preform thickness in example 1, so a narrow gap (10 mm thick) exists between the top of the preform and upper surface of the mould. The permeability of the CSM preform can be computed from:

$$
K\left(v_{f}\right)=3.07 \times 10^{-8} e^{-12.97 v_{f}}\left(m^{2}\right) .
$$

Table 2. Process parameters

\begin{tabular}{|c|c|c|}
\hline \multirow{2}{*}{ Injection flow rate } & Example 1 & Example 2 \\
\cline { 2 - 3 } & $51.2 \mathrm{ml} / \mathrm{s}$ & $51.2 \mathrm{ml} / \mathrm{s}$ \\
\hline$\mu$ & $0.4 \mathrm{~Pa} \cdot \mathrm{s}$ & $0.4 \mathrm{~Pa} \cdot \mathrm{s}$ \\
\hline$h_{\text {ini }}$ & $80 \mathrm{~mm}$ & $70 \mathrm{~mm}$ \\
\hline$h_{p, \text { ini }}$ & $70 \mathrm{~mm}$ & $70 \mathrm{~mm}$ \\
\hline$v_{f, \text { ini }}$ & 0.35 & 0.35 \\
\hline$h_{\text {final }}$ & $60 \mathrm{~mm}$ & $60 \mathrm{~mm}$ \\
\hline$F_{\text {total }}$ & $4 \mathrm{kN}$ & $4 \mathrm{kN}$ \\
\hline
\end{tabular}

Numerical simulations of the mould filling patterns in both examples are shown in Fig. 10.

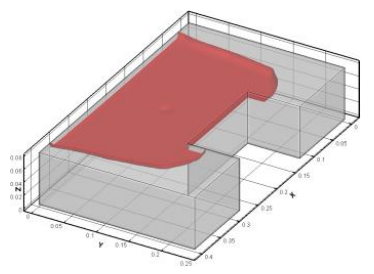

$10.22 \mathrm{~s}$

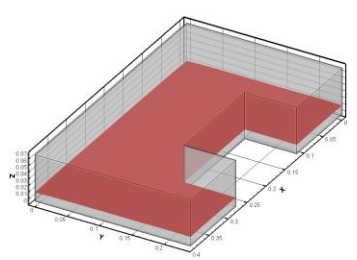

70.9 s, end of gap closure

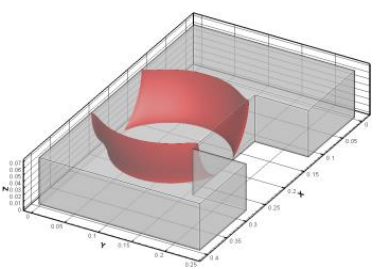

$21.5 \mathrm{~s}$

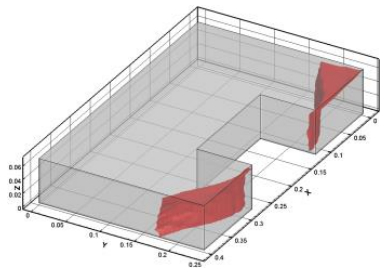

$137.1 \mathrm{~s}$

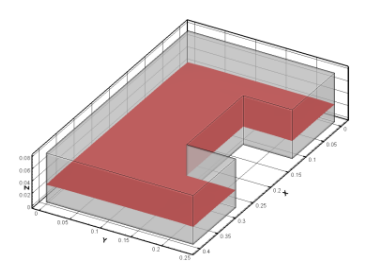

$58.8 \mathrm{~s}$, end of resin injection

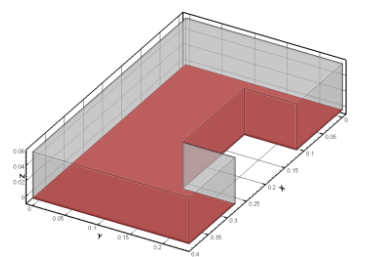

383 s, end of mould-filling

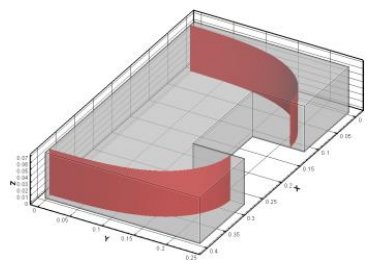

$58.8 \mathrm{~s}$, end of resin injection

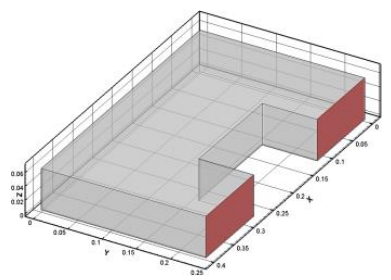

395.9 s, end of mould-filling
Fig. 10. Flow patterns: $a-$ example $1 ; b$-example 2

The total resin injection times for the two examples are both $58.8 \mathrm{~s}$ since the constant flow rate strategy is used. In example 1, resin flows into the narrow gap firstly and then complete mould filling occurs, and the resin flows during 
the last two filling stages (see Fig. 10 a) can be assumed to be one-dimensional (see Fig. 2). Conversely, resin directly infiltrates the preform in all directions in example 2, so a 3D irregular flow front is formed. Fig. 11 presents the injection pressure evolutions for both examples. In example 1 , the injection pressure is negligible before the open gap is fully filled at $t=15 \mathrm{~s}$, then it increases linearly which is agree with the one-dimensional flow. On the contrary, an extremely high injection pressure is produced in example 2 because of the inexistence of gap.

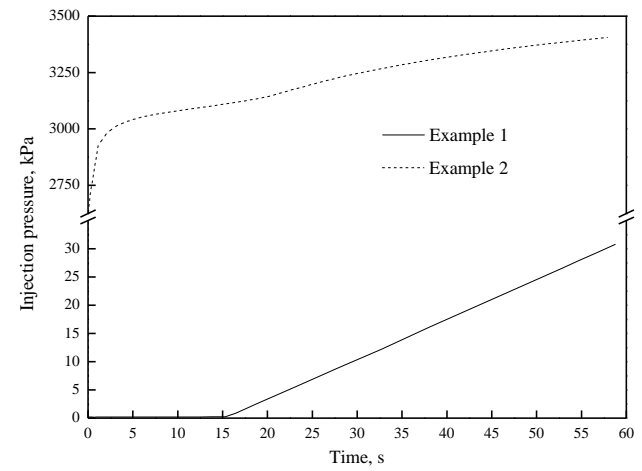

Fig. 11. Injection pressure traces

The mould compression speed and cavity thickness evolutions of the two examples are presented in Fig. 12.
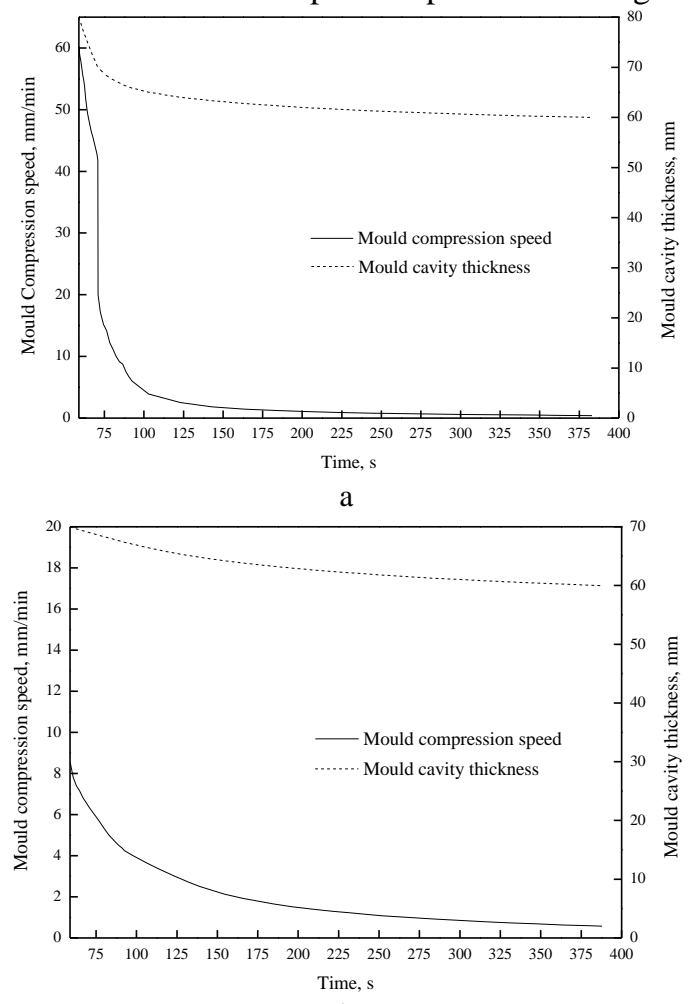

b

Fig. 12. Mould compression speed and cavity thickness traces: a example $1 ; b$ - example 2

Similar to the 1D flow, both the compression speeds of the two examples exhibit decreasing trends. It should be noted that in example 1 , a plunge can be found at $t=70.9 \mathrm{~s}$, because the open gap is closed completely and the preform starts to be compacted at this time. Eq. 2 and Eq. 6 are applied to compute the compression speeds before and after this moment, respectively. Although the initial compression speed of example 1 is much higher than that of example 2, the difference between the total filling times of the two examples is much less, this is because the compression speed of example 1 falls faster as can be seen in Fig. 12. The reason for the above phenomenon is that the decrease of the resin counter force of example 2 is faster than that of example 1 as shown in Fig. 13, so the preform compaction force increases faster in example 2 according to Eq. 3, as a result, its compression speed falls slower.

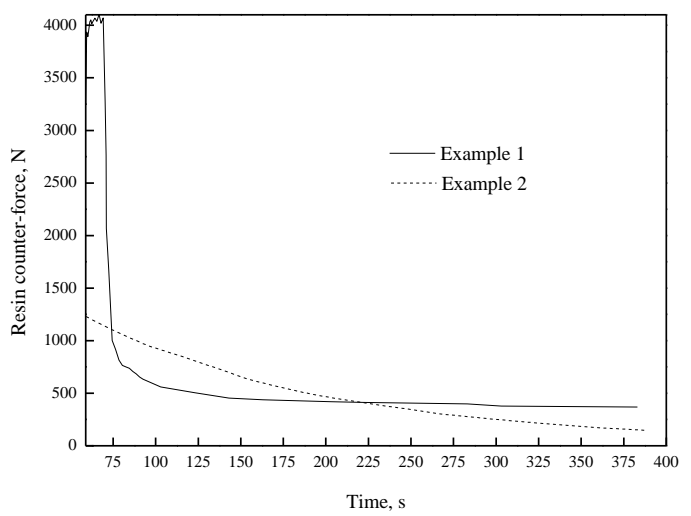

Fig. 13. Resin counter force traces

From the above simulation results, we can find that under a constant champing force, the mould compression speed decreases rapidly with the increasing of the fiber volume fraction, which may lead to a longer process time. Increasing the clamping force during preform compaction is one of the alternative solutions, but the higher mould, equipment and control requirments will be needed.

\section{CONCLUSIONS}

CRTM increasingly becomes an important processing technology to fabricate large-scale or high fiber content composite parts, while the full 3D simulation for the forcecontrolled CRTM filling process is unacquirable until now since the complicated resin flow and preform deformation. Especially for the force-controlled CRTM in which the coupled resin flow and mould compression behaviors need to be solved. In this paper, the total applied clamping force was analyzed firstly, the mould compression speed calculation methods for both gap closure and preform compaction stages were proposed based on the equivalent spring system. The viscoelastic compaction model was adopted to describe the preform compaction characteristics, and the VOF two-phase model is established to express the resin-air flow in narrow gap and preform simultaneously, in which the narrow gap is considered as $3 \mathrm{D}$ area without flow resistance. Then the 3D numerical solving method of the above mathematical models was developed based on the VOF module of Fluent software, in this method, the dimension changing of mould cavity is implemented by moving mesh technology, and the master-slave element method is used to simulate the resin squeezing from the infiltrated preform. Finally, the above simulation method was verified by comparisons with analysis results, and two three-dimensional simulation examples have also been presented. 


\section{Nomenclature}

$A=$ Surface area of the mould

$A_{i}=$ Aarea of the $i$-th preform subpart contacted with the moving platen of the mould

$\mathrm{C}=$ Resin volume fraction in a computational cell

$E_{i}=$ Stiffness coefficient of the $i$-th subpart

$F_{f}=$ Preform reaction force

$F_{f, i}=$ Compaction force exerted on the $i$-th subpart of the preform

$F_{r}=$ Resin reaction force

$F_{\text {total }}=$ Total applied clamping force

$h=$ Mould cavity thickness

$h_{\text {ini }}=$ Initial thickness of mould cavity

$h_{\text {final }}=$ Desired thickness of the final part

$h p=$ Preform thickness

$h_{p, i n i}=$ Initial preform thickness

$K=$ Preform permeability

$K_{z z}=$ Through thickness permeability value of the preform

$k=$ Kozeny-Carman constant

$l=$ Thickness of the saturated preform

$N_{\alpha}=$ Number of exponential terms

$N_{\beta}=$ Degree of polynomial

$p=$ Resin pressure

$p_{i n}=$ Injection pressure

$p_{\text {out }}=$ Outlet pressure

$r_{c}=$ Mould compression speed

$r_{p, c}=$ Compaction velocity

$r_{p, c}{ }^{r e f}=$ Reference compaction speeds

$s_{\text {wet }}=$ Infiltration state

$u=$ Flow velocity

$\overline{\boldsymbol{u}}=$ Volume averaged flow velocity

$v f=$ Preform fiber volume fraction

$v_{f}^{\text {dat }}=$ The datum volume fraction

$v f, i n i=$ Initial fiber volume fraction of the preform

$v_{f}^{\text {ref }}=$ Reference volume fractions

$\sigma_{\alpha}\left(r_{p, \mathrm{c}}\right)=$ Stress as a function of compaction speed at a reference fiber content

$\sigma_{\beta}\left(v_{f}\right)=$ Stress response as a function of fiber content at a

reference compaction speed

$\sigma_{f}=$ Preform compaction stress

$\sigma_{f, i}{ }^{n-1}=$ Compaction stress on the $i$-th subpart of the preform

$\mu=$ Resin viscosity

$\Phi=$ Fluid physical properties

$\rho=$ Resin density

\section{Acknowledgments}

The presented work was supported by the National Natural Science Foundation of China (grant number 51605057); the Basic Science and Advanced Technology Research Project of Chongqing (grant number cstc2016jcyjA0456); the China Postdoctoral Science Foundation (grant number 2016M600721); the SelfPlanned Task of State Key Laboratory of Mechanical Transmission (grant number SKLMT-ZZKT-2016Z04); and the Fundamental Research Funds for the Central Universities(grant number 106112017CDJXY110001).

\section{REFERENCES}

1. Um, M.K., Lee, W.I. A Study on the Mould Filling Process in Resin Transfer Moulding Polymer Engineering and Science 31 (11) 1991: pp. 765-771. https://doi.org/10.1002/pen.760311102

2. Yoo, Y.E., Lee, W.I. Numerical Simulation of the Resin Transfer Mould Filling Process Using the Boundary Element Method Polymer Composites 17 (3) 1996: pp. 368-374. https://doi.org/10.1002/pc.10623

3. Voller, V.R., Peng, S. An Algorithm for Analysis of Polymer Filling Moulds Polymer Engineering and Science 35 (22) 1995: pp. 1758-1765. https://doi.org/10.1002/pen.760352205

4. Lam, Y.C., Joshi, S.C., Liu, X.L. Numerical Simulation of Mould-Filling Process in Resin Transfer Moulding Composites Science Technology 60 2000: pp. 845-855. https://doi.org/10.1016/S0266-3538(99)00192-X

5. Simacek, P., Advani, S.G. A Numerical Model to Predict Fiber Tow Saturation During Liquid Composite Molding Composites Science Technology 63 2003: pp. 1725-1736. https://doi.org/10.1016/S0266-3538(03)00155-6

6. Gantois, R., Cantarel, A., Dusserre, G., Félices, J.N., Schmidt, F. Numerical Simulation of Resin Transfer Molding Using BEM and Level Set Method International Journal of Material Forming 3 (S1) 2010: pp. 635-638. https://doi.org/10.1007/s12289-010-0850-9

7. Vanegas, J.D., Patino, I.D. Filling Simulation of the RTM Process in Isotropic Homogeneous/Non-Homogeneous Media Using the Boundary Element Method Advanced Composite Materials 24 (2) 2015: pp. 113-139. https://doi.org/10.1080/09243046.2013.879401

8. Pham, X.T., Trochu, F., Gauvin, R. Simulation of Compression Resin Transfer Moulding with Displacement Control Journal of Reinforced Plastic and Composites 17 1998: pp. $1525-1556$.

https://doi.org/10.1177/073168449801701704

9. Yang, B., Jin, T., Li, J., Bi, F. Three-Dimensional Numerical Simulation of Mould Filling Process in Compression Resin Transfer Moulding Applied Composite Materials 22 2015: pp. 209-230. https://doi.org/10.1007/s10443-014-9402-7

10. Bickerton, S., Buntain, M.J. Modeling Forces Generated within Rigid Liquid Composite Moulding Tools. Part B: Numerical Analysis Composites Part A: Applied Science and Manufacturing 38 2007: pp. $1742-1754$. https://doi.org/10.1016/j.compositesa.2006.11.001

11. Walbran, W.A., Bickerton, S., Kelly, P.A. Measurements of Normal Stress Distributions Experienced by Rigid Liquid Composite Moulding Tools Composites Part A: Applied Science and Manufacturing 40 2009: pp. 1119-1133. https://doi.org/10.1016/j.compositesa.2009.05.004

12. Walbran, W.A., Verleye, B., Bickerton, S., Kelly, P.A. Prediction and Experimental Verification of Normal Stress Distributions on Mould Tools during Liquid Composite Moulding Composites Part A: Applied Science and Manufacturing 43 2012: pp. 138-149. https://doi.org/10.1016/j.compositesa.2011.09.028

13. Simacek, P., Advani, S.G., Iobst, S.A. Modeling Flow in Compression Resin Transfer Molding for Manufacturing of Complex Lightweight High- Performance Automotive Parts Journal Composite Materials 42 2008: pp. 2523-2545. https://doi.org/10.1177/0021998308096320

14. Shojaei, A. Numerical Simulation of Three-Dimensional Flow and Analysis of Filling Process in Compression RTM 
Composites Part A: Applied Science and Manufacturing 37 2006: pp. $1434-1450$.

https://doi.org/10.1016/j.compositesa.2005.06.021

15. Chang, C.Y. Simulation of Compression Effect on Filling Process in Compression Resin Transfer Molding Advanced Composite Materials $20(2)$ 2011: pp. $197-211$. https://doi.org/10.1163/092430410X547038

16. Bhat, P., Merotte, J., Simacek, P., Advani, S.G. Process Analysis of Compression Resin Transfer Molding Composites Part A: Applied Science and Manufacturing 40 2009: pp. $431-441$. https://doi.org/10.1016/j.compositesa.2009.01.006

17. Merotte, J., Simacek, P., Advani, S.G. Flow Analysis during Compression of Partially Impregnated Fiber Preform under Controlled Force Composites Science Technology 70 2010: pp. $725-733$. https://doi.org/10.1016/j.compscitech.2010.01.002

18. Merotte, J., Simacek, P., Advani, S.G. Resin Flow Analysis with Fiber Preform Deformation in Through Thickness Direction during Compression Resin Transfer Molding Composites Part A: Applied Science and Manufacturing 41 2010: pp. 881-887. https://doi.org/10.1016/j.compositesa.2010.03.001

19. Verleye, B., Walbran, W.A., Bickerton, S., Kelly, P.A. Simulation and Experimental Validation of Force Controlled Compression Resin Transfer Molding Journal of Composite Materials 45 (7) 2011: pp. 815-829. https://doi.org/10.1177/0021998310376110

20. Walbran, W.A., Bickerton, S., Kelly, P.A. Simulation and Experimental Validation of Mould Tooling Forces in RTM and CRTM for Nonplanar Components Polymer Composites 36 2015: pp. 591-603. https://doi.org/10.1002/pc.22976

21. Mamoune, A., Saouab, A., Ouahbi, T., Park, C.H. Simple Models and Optimization of Compression Resin Transfer
Molding Processes Journal of Reinforced Plastics and Composites 30 (19) 2011: pp. 1629-1648. https://doi.org/10.1177/0731684411421539

22. Yang, B., Jin, T., Li, J., Bi, F. Simulating the Resin Flow and Stress Distributions on Mould Tools during Compression Resin Transfer Molding Journal of Reinforced Plastics and Composites 33 (14) 2014: pp. 1316-1331. https://doi.org/10.1177/0731684414528831

23. Kelly, P.A. A Viscoelastic Model for the Compaction of Fibrous Materials Journal of the Textile Institute 102 (8) 2011: pp. 689-699. https://doi.org/10.1080/00405000.2010.515103

24. Kelly, P.A., Umer, R., Bickerton, S. Viscoelastic Response of Dry and Wet Fibrous Materials during Infusion Processes Composites Part A: Applied Science and Manufacturing 37 2006: pp. $868-873$. https://doi.org/10.1016/j.compositesa.2005.02.008

25. Simacek, P., Eksik, O., Heider, D., Gillespie, J.W., Advani, S. Experimental Validation of Post-Filling Flow in Vacuum Assisted Resin Transfer Molding Processes Composites Part A: Applied Science and Manufacturing 43 2012: pp. $370-380$. https://doi.org/10.1016/j.compositesa.2011.10.002

26. Govignon, Q., Bickerton, S., Kelly, P.A. Simulation of the Reinforcement Compaction and Resin Flow during the Complete Resin Infusion Process Composites Part A: Applied Science and Manufacturing 41 2010: pp. 45-57. https://doi.org/10.1016/j.compositesa.2009.07.007

27. Yang, B., Tang, Q., Wang, S., Jin, T., Bi, F. ThreeDimensional Numerical Simulation of the Filling Stage in Resin Infusion Process Journal of Composite Materials 50 (29) 2016: pp. $4171-4186$. https://doi.org/10.1177/0021998316631809 